\title{
Can bulk-fill resin restorations be an alternative to resin-modified glass ionomer cement restorations in primary molars of toddlers? A randomized clinical trial protocol.
}

\author{
¿Pueden las restauraciones de resina bulk-fill \\ ser una alternativa a las restauraciones de cemento \\ de ionómero de vidrio modificado con resina en los \\ molares primarios en niños preescolares? \\ Un protocolo de ensayo clínico aleatorizado
}

Isabela Coelho Novaes. ${ }^{1}$

Luna Chagas Clementino. ${ }^{1}$

Fernanda Morais Ferreira. ${ }^{1}$

Tathiane Lenzi. ${ }^{2}$

Marco Aurélio Paschoal. ${ }^{1}$

Saul Martins Paiva. ${ }^{1}$

Fernanda Bartolomeo Freire-Maia. ${ }^{1}$

Paulo Antônio Martins-Júnior. ${ }^{1}$

Affiliations:

${ }^{1}$ Department of Child and Adolescent Oral Health, Faculty of Dentistry, Federal University of Minas Gerais, Brazil.

${ }^{2}$ Department of Surgery and Orthopedics, Faculty of Dentistry, Federal University of Rio Grande do Sul, Brazil.

Corresponding author: Paulo Antônio Martins-Júnior. Department of Child and Adolescent Oral Health, Faculty of Dentistry, Federal University of Minas Gerais, Brazil. Av. Antônio Carlos, 6627, Pampulha, Belo Horizonte, MG, Brasil. E-mail: pauloa-martinsjunior@ufmg.br

Receipt : 06/11/2020 Revised: 04/14/2021 Acceptance: 06/30/2021

Cite as: Novaes IC, Clementino LC, Ferreira FM, Lenzi T, Paschoal MA, Paiva SM, Freire-Maia FB \& Martins-Júnior PA. Can bulk-fill resin restorations be an alternative to resin-modified glass ionomer cement restorations in primary molars of toddlers? A randomized clinical trial protocol.

J Oral Res 2021; 10(3):1-10.

Doi:10.17126/joralres.2021.029

1
Abstract: Background: The aim of this study was to elaborate a randomized clinical trial protocol to evaluate the effectiveness of class I restorations in resin-modified glass ionomer cement (RMGIC) and bulk-fill resin in primary molars with untreated early childhood caries in toddlers. Material and Methods: A total of 59 toddlers up to 36 months old with at least two primary molar teeth with untreated dental caries of single surface on different sides of the mouth will be selected at the Pediatric Dentistry Clinics of the Faculty of Dentistry at Federal University of Minas Gerais (UFMG), Brazil. Teeth with untreated dental caries in the left and right sides of each patient's mouth will be randomly distributed into 2 groups: Group 1 (Control): encapsulated RMGIC restoration with Riva light cure (SDI, Florida, USA) and Group 2 (Test): Filtek bulk-fill composite resin restoration (3M/ESPE, St. Paul, USA) with universal single bond adhesive system (3M/ESPE, St. Paul, USA). A single trained dentist will perform all restorative procedures. The restorations will be evaluated after 1, 6, 12, 18 and 24 months by two trained and calibrated examiners. Cost-efficacy analysis will be carried out. KaplanMeier survival analysis, Log-rank test, Cox regression, Poisson regression analysis, Mann-Whitney test or Kruskal-Wallis will be performed to analyze data. Conclusion: The protocol will make it possible to determine the most efficacy material for the restoration of cavities in cavities in primary molars of toddlers.

Keywords: Cost-effectiveness analysis; Molar; Tooth, Deciduous; Clinical Trial; Dental Materials; Child, Preschool.

Resumen: Antecedentes: El objetivo de este estudio fue elaborar un protocolo de ensayo clínico aleatorizado para evaluar la efectividad de las restauraciones de clase I en cemento de ionómero de vidrio modificado con resina (RMGIC) y resina bulk-fill en molares primarios con caries de la primera infancia no tratadas en niños preescolares. Material y Métodos: Un total de 59 niños de hasta 36 meses de

ISSN Print 0719-2460 - ISSN Online 0719-2479. Attribution 4.0 International (CC BY 4.0). www.joralres.com/2021 
edad con al menos dos molares temporales con caries no tratada de superficie única en diferentes lados de la boca serán seleccionados en las Clínicas de Odontología Pediátrica de la Facultad de Odontología de la Universidad Federal de Minas Gerais (UFMG), Brasil. Los dientes con caries no tratada en los lados izquierdo y derecho de la boca de cada paciente se distribuirán aleatoriamente en 2 grupos: Grupo 1 (Control): restauración RMGIC encapsulada con fotopolimerización Riva (SDI, Florida, EE. UU.) Y Grupo 2 (Prueba): Restauración de resina compuesta bulk-fill Filtek (3M / ESPE, St. Paul, EE. UU.) con sistema adhesivo de unión simple universal (3M / ESPE, St. Paul, EE. UU.). Un solo dentista capacitado realizará todos los procedimientos

\section{INTRODUCTION.}

Early childhood caries (ECC) is the most prevalent chronic disease in children, representing a public health problem. ${ }^{1}$ The painful symptoms caused by untreated dental caries can negatively interfere in sleep, speech and eating which, in particular, can hinder the intake of important nutrients for children's growth and development ${ }^{2}$ In this sense, studies have been conducted about the prevention, diagnosis, risk assessment, as well as clinical approach to ECC. ${ }^{3-7}$

In Pediatric Dentistry, certain patterns of behavior related to the physical, chemical, mechanical and biological properties of materials can vary when comparing primary and permanent teeth. ${ }^{8}$ The choice of restorative material must be made individually. Also, minimally invasive approaches for the treatment of carious lesion can be especially interesting in primary teeth due to the smaller thickness of enamel and dentin and the faster progression of the carious lesion in relation to permanent teeth, in addition to reducing the risk of pulp exposure. ${ }^{9}$ Therefore, adhesive restorative materials, such as glass ionomer cement (GIC) and composite resin associated with adhesive system, become necessary for greater preservation of the dental structure with adequate anatomical and functional restoration.

The GIC has the ability to initial rapid fluoride release, followed by a slow diffusion of fluoride over long periods of time. The RMGIC was created to overcome the low tensile and compressive strength of conventional GIC. RMGIC has shown higher values of de restauración. Las restauraciones serán evaluadas después de 1, 6, 12, 18 y 24 meses por dos examinadores capacitados y calibrados. Se llevará a cabo un análisis de coste-eficacia. Se realizarán análisis de supervivencia de Kaplan-Meier, prueba de rango logarítmico, regresión de Cox, análisis de regresión de Poisson, prueba de Mann-Whitney o Kruskal-Wallis para analizar los datos. Conclusión: El protocolo permitirá determinar el material más eficaz para la restauración de caries en molares temporales de niños preescolares.

Palabra Clave: Análisis Costo-Beneficio; Diente Molar; Diente Primario; Ensayo Clínico; Materiales Dentales; Preescolar.

flexural strength, flexural toughness and fracture than conventional GIC. ${ }^{10}$ Recently, bulk-fill resins were introduced in the market employing new formulations of composite resin ${ }^{11}$ to be used in posterior teeth in a single increment with curing depths up to $4 \mathrm{~mm}$ or $5 \mathrm{~mm}$ with minimal polymerization contraction. ${ }^{12}$ Similar survival outcomes have been reported for conventional composite resins and single-increment restorations in permanent teeth after 1 to 3 years of follow-up. ${ }^{13}$ Recently, a systematic review found no significant differences between RMGIC and composite resin, in addition to showing that conventional GIC presented the highest risk of failure compared to all other conventional restorative materials used. ${ }^{14}$ However, no studies that evaluated encapsulated RMGIC and bulk-fill resins or studies with toddlers were included.

The use of encapsulated RMGIC could be advantageous not only because of the increase in tensile strength, but also due to the lower probability of error during spatulation, ease of application and better control of working time. On the other hand, the possibility of applying bulk-fill resins in a single increment can be particularly useful in posterior restorations where the time is a cause for concern, as in the case of younger, uncooperative, anxious toddlers, as well as patients with special needs. ${ }^{15}$ Although recent studies have evaluated the clinical performance of high viscosity GIC and bulk-fill resins in primary molars, they present methodological and conceptual particularities, such as pragmatic trials ${ }^{16}$ or 
no direct comparison of RMGIC and bulk-fill resin in the same patient. ${ }^{17,18}$

Therefore, the aim of this study was to develop a double-blind, split-mouth, randomized clinical trial protocol to evaluate the efficacy of occlusal restorations in RMGIC and bulk-fill resin in primary molars with untreated early childhood caries in toddlers. The secondary aims were:

(i) to compare the survival of the restorations 1, 6, 12, 18 and 24 months of follow-up;

(ii) to evaluate the post-operative sensitive between restorations;

(iii) to compare the cost-efficacy of treatments; and

(iv) to assess the operator's preference in relation to one of the treatment options.

\section{MATERIALS AND METHODS.}

The present randomized clinical trial protocol is described according to the Standard Protocol Items for Reporting in Trials (SPIRIT). (Figure 1)

\section{Ethical issues}

This protocol received approval from the Human Research Ethics Committee of the Federal University of Minas Gerais (UFMG), Brazil (CAAE: 12891619.7.0000.5149) and was registered with the Brazilian Registry of Clinical Trials (ReBEC) (http:// www.ensaiosclinicos.gov.br) (UTN number: U11111239-2847). The study will be conducted at the Faculty of Dentistry of Federal University of Minas Gerais. A signed informed consent form will be obtained from the parents/guardians of the toddlers before participating in the study. All participants will be coded by a number to guarantee the confidentiality of the information.

\section{Study design}

The present study is a protocol for a double-blind, split-mouth, randomized clinical trial. By testing both materials on the same patient, both restorations will be submitted to the same dietary conditions, saliva, oral hygiene habits, masticatory efforts and toddler's behavior, which decreases the influence of bias and confounding factors. ${ }^{19}$

The restorative procedures will be performed by a single operator aided by two assistants. The operator will receive instructions on selective removal of carious tissue, ${ }^{9}$ as well as will perform a pre-clinical activity for technical training on the use of restorative materials, strictly in accordance with manufacturers recommendations. The restorations will be evaluated longitudinally by two examiners properly calibrated to the evaluation criteria, and who will be unaware of the research objectives. Toddlers and parents/guardians will be blinded to the procedures, since it will not be discussed directly with them on which teeth each restorative material will be placed. In addition, toddlers under 36 months of age hardly have cognitive ability to understand this differentiation. ${ }^{20}$ For the analysis, the statistician will be blinded to the groups and outcomes through coding (restoration 1 and restoration 2).

\section{Sample calculation}

The sample size was calculated based on the survival rate of the restorations with a statistical power of $80 \%$ and a significance level of 5\%. A 98.3\% survival rate for RMGIC was considered ${ }^{21}$ and an absolute difference of 15\% between survival rates between resin-modified GIC and bulk-fill resin in a two-tailed hypothesis, resulting in a minimum sample of 49 patients. It was added $20 \%$ to the calculation result to predict possible loss of follow-up, totaling 59 patients to be recruited.

\section{Selection of patients}

Participants in this study will be selected from among all healthy toddlers who are under treatment or on the waiting list for care at the Faculty of Dentistry of UFMG, Brazil. All toddlers up to 36 months of age who present at least two cavitated dental caries restricted to the occlusal surface in primary molars detectable in dentin, characterized as medium and deep lesions, ${ }^{9}$ being one lesion on each side of the mouth (right and left), will be eligible for this study. Besides that, the selected tooth has to present its antagonist. Only toddlers whose parents/guardians sign the informed consent form will be included. No additional incentives for participants to join the study will be provided. Even toddlers with uncooperative behavior will be included in this study, since this behavior is common in clinical practice in Pediatric Dentistry. ${ }^{16}$

Toddlers whose carious lesions are affecting the pulp chamber or at risk of pulp exposure, who present fistula or abscess, pulp exposure, history of spontaneous pain or tooth mobility associated with decayed teeth will be excluded. In addition, molar 
teeth with other restorations, enamel defects or endodontic treatment that present carious lesions associated with an existing restoration or that do not stabilize the clamp for absolute isolation will also be excluded.

\section{Clinical examinations}

The clinical examinations will be performed at the Pediatric Dentistry Clinic of UFMG, with the toddler lying in a dental chair and the teeth will be evaluated under artificial light. Initially, the visible plaque index and the gingival bleeding index will be evaluated. For the visible plaque index, teeth in the process of eruption and with partially destroyed crowns will be excluded. The gingival bleeding index will be evaluated by the number of bleeding points after flossing the gingival sulcus of all teeth.

Then, prophylaxis will be done so that the teeth are examined clean. For clinical examinations, the teeth will be assessed, cleaned and dried. To evaluate the presence of dental caries, the International Caries Detection and Assessment System (ICDAS II) will be used. ${ }^{22}$ The ICDAS II score system ranges from 0 (healthy tooth) to 6. Scores 1 and 2 are used for white spot lesions, while scores $\geq 3$ determine different degrees of cavitation. ${ }^{22}$

The clinical consequences of untreated dental caries will be measured using the pufa index. ${ }^{23}$ Interproximal radiographs on the right and left sides will be performed in all patients to assist in the correct diagnosis of the presence, extension and depth of dental caries lesions. All procedures will strictly follow international biosafety principles.

\section{Sociodemographic data}

Data about the toddlers sociodemographic conditions will be collected from a questionnaire to be answered by the parents/guardians, based on a previous study. ${ }^{24}$ The toddler's age and sex, parental marital status, age of mother and father, parental educational level, number of siblings, monthly family income, the number of people that live with the same income and who is the primary caregiver of the toddler will be collected. Parents will receive a threeday dietary diary to determine each toddler's index of sucrose consumption.

\section{Randomization}

The randomization will be carried out through: https://www.randomization.com by a researcher blinded to the study. Sequentially numbered sealed envelopes will be used. Each envelope will have the type of restorative procedure (RMGIC or bulk-fill resin) and the corresponding side that will receive the procedure (right or left). In addition, the order in which the restorations will be carried out will also be randomized.

\section{Study groups}

The teeth of the toddlers will be randomly divided into two groups:

Group 1 (Control): encapsulated RMGIC restoration with Riva light cure (SDI, Florida, USA);

Group 2 (Test): Filtek bulk-fill composite resin restoration (3M/ESPE, St. Paul, USA) with universal single bond adhesive system (3M/ESPE, St. Paul, USA).

\section{Interventions}

All restorative procedures will be carried out after prophylaxis. Local anesthesia (lidocaine 2\% with epinephrine hydrochloride 1: 100,000 IU) will be used to decrease the discomfort caused by putting the clamp for absolute isolation, preceded by topical anesthesia (benzocaine 200 mg/g, DFL, Rio de Janeiro, Brazil). Participants will be subject to interventions on two different occasions. In each appointment, the removal of decayed tissue and restoration of only one tooth will be held. Clinical parameters related to dentin texture and color will be used to guide the removal of decayed tissue. ${ }^{9}$ In medium depth lesions, selective removal will be carried out, maintaining a dentin of firm consistency over the pulp, while in deep lesions, a layer of decayed tissue with a "soft" consistency will be left to avoid exposure and "stress" to the pulp. The surrounding walls in both lesions will have the decayed dentin removed until dentin is of firm consistency to ensure a good seal and survival of the restoration. ${ }^{9}$ Thus, after the removal of decayed tissue, the cavity will be measured using a millimeter-periodontal probe. All restorations will be done under absolute isolation.

Group 1: The cavity conditioning will be done with Riva Conditioner (SDI, Florida, USA) for 10 seconds followed by abundant washing with water. The excess of water will be removed carefully to not completely dry the tooth surface. Subsequently, the capsule will be activated and placed in a compatible mixer (4000rpm -48000rpm) and agitated for 10 seconds. 
The capsule will be positioned in the Riva applicator for application in all cavities, followed by photo activation for 20 seconds with a device with visible light intensity (470 nm wavelength). Finally, the restoration will be superficially covered with Riva Coat (SDI, Florida, USA) to minimize syneresis and imbibition. Parents/ guardians will be informed that the toddler should not expose the restoration to masticatory forces for at least 1 hour after the procedure.

Group 2: A layer of universal adhesive system (3M/ESPE, St. Paul, USA) will be applied in the cavity, with scrubbing, for 20 seconds, followed by the application of compressed jet air for 5 seconds and photo activation for 10 seconds with visible light intensity (470nm wavelength). Then, the Filtek bulkfill composite resin (3M/ESPE, St. Paul, USA) will be applied in a single increment of up to $4 \mathrm{~mm}$, followed by photo activation during 20 seconds of each dental surface.

Possible occlusal interferences will be checked, and occlusal adjustments will be made with fine-grained diamond burs number 3118F (KG Sorensen, São Paulo, Brazil) in high rotation under refrigeration. All patients will also receive guidance with their parents/ guardians about healthy dietary and oral hygiene habits. If any sign or symptom of allergy to any of the components of dental materials is diagnosed, the procedures will be interrupted and the necessary care will be immediately provided to the patient, who will be excluded from the research.

\section{Evaluation of post-operative sensitivity}

Possible sensitivity was hypothesized in patients undergoing restorations. As a result, post-operative sensitivity has become an interesting variable to be evaluated. Therefore, the Brazilian version of the Dental Discomfort Questionnaire (DDQ-B) ${ }^{25}$ will be used. The DDQ-B is a proxy instrument for children from 0 to 5 years old and it uses a 3-point scale to choose the frequency of each behavior (never, sometimes or always) for the following: "bites with back teeth instead of front teeth"; "cry during meals"; "has trouble for chewing"; "chew only on one side"; "suddenly cry at night". Higher scores indicate higher perception of pain. The questionnaire will be applied before and 24 hours after each appointment for response comparisons.

\section{Follow-up}

All evaluations will be performed by two trained and calibrated examiners (Kappa >0.70). Toddlers will return for follow-up at 1, 6, 12, 18 and 24 months after the restorative procedures for the evaluation of the restorations according to Roeleveld et al. ${ }^{26}$

The width and depth of marginal defects, the surface wear and the excess or lack of material will be measured with a CPI ball pointed periodontal probe. Parents/guardians will be encouraged to bring their children for the follow-up at defined periods, which coincide with routine preventive maintenance evaluation adopted at the Pediatric Dentistry Clinic of UFMG. Thus, researchers expect to retain patient participation until the follow-up period proposed in the research is completed.

\section{RESULTS.}

The main outcome of this study will be the survival of RMGIC and bulk-fill composite resin restorations.

Survival of restorations: Survival will be evaluated 1, 6, 12, 18 and 24 months after the treatment by two trained and calibrated examiners. Intact restorations and those with small failures that receive scores from 00 to 10 will be considered successful. ${ }^{26}$ The restored teeth that receive scores between 11 and 40 will be considered as failures;

\section{Post-operative sensitivity}

The sensitivity will be evaluated before and after the treatments using the DDQ-B25;

\section{Cost-efficacy}

The cost-efficacy ratio will be used. The ratio among the difference between the costs of implementing the different restorative treatments and the difference between the effects will be calculated for each material. The mean cost per treatment will be quantified for both groups. For the calculation of direct costs, the prices of materials that will be used in each procedure will be considered. To calculate the professional cost, the time spent in each appointment will be calculated, and a conversion in hours will be done and multiplied by the dentist's medium income per hour, as reported by the Ministry of Labor and Employment (US \$ 36.23).

To estimate the cost of the procedure, the variable cost, that includes the depreciation of electricity 
and equipment, and the costs of materials will be considered. To calculate the depreciation of the equipment (peripherals, dental chair and instruments), the life span of five years and a monthly use of 160 hours will be considered, using an estimated hourly value of US \$1.81. The efficacy effects will be obtained by evaluating the survival rate of the restorations.

Operator's preference: The operator's preference will be evaluated through a questionnaire developed specifically for this purpose containing questions about the ease of execution of the restorative procedure, considering the ease of applying and manipulation of the material.

\section{Statistical analysis}

The data will be digitized and analyzed using the Statistical Package for Social Sciences program (SPSS for Windows, version 20.0; SPSS Inc., Chicago, III., USA). Frequency distributions and descriptive data analysis will be conducted. First, a normality test will be performed to determine if the data are normally distributed. Associations between toddlers who showed or not failure in the restorations and independent sociodemographic variables will be tested by the chi-square test.

To compare the treatments and the survival of restorations, Kaplan-Meier survival analysis and the

Figure 1. Flowchart of the randomized clinical trial protocol to evaluate the efficacy of occlusal restorations in RMGIC and bulk-fill resin in primary molars with untreated early childhood caries in toddlers.

\section{Inclusion criteria}

- Toddlers ASA I up to 36 months of age. At least to medium or deep cavitated dental caries restricted to the occlusal surface in primary molars, being at least one lesion at each side of the mouth (right and left). Toddlers whose parents/guardians sign the informed consent.

\section{Exclusion criteria}

- Toddlers with teeth affecting the pulp chamber or at risk of pulp exposure.

- Toddlers with teeth presenting fistula/abscess, history of spontaneous pain or mobility associated with decayed teeth.

- Molar teeth with other restorations, enamel defects or endodontic treatment.

- Teeth unable to stabilize a clamp for absolute isolation.

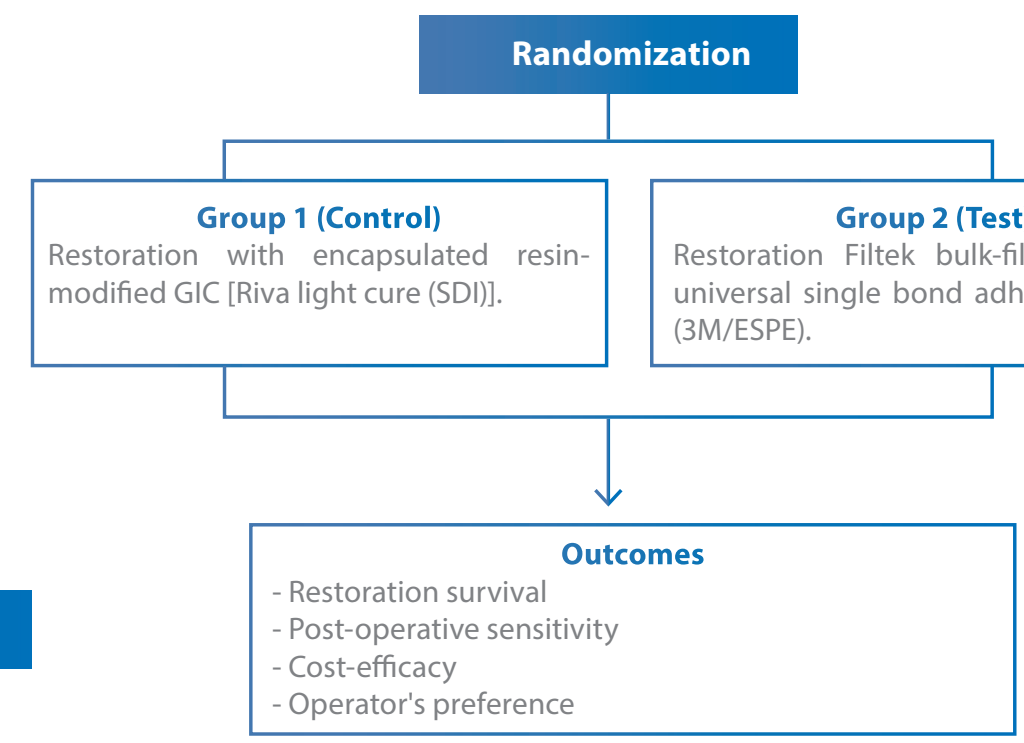


Log-rank test will be used. The association between survival of the restorations and the experience of dental caries will be evaluated with Cox regression. Factors associated with the survival of the restorations will be evaluated by Poisson regression analysis. Associations between the type of restoration and the post-operative sensitivity will be evaluated by the Mann-Whitney or Kruskal-Wallis test. The level of significance considered for all data analyzed will be set at $5 \%$.

\section{DISCUSSION.}

The main objective of this study was to develop a protocol of randomized clinical trial to evaluate the efficacy of occlusal restorations of RMGIC and bulk-fill composite resin with a single increment and universal adhesive system in self-etching mode in primary molars with untreated ECC in toddlers. The present methodology was developed with rigorous conditions to observe the behavior of the materials under ideal conditions. In the current literature, only one publication of a pragmatic clinical trial protocol was found comparing the effectiveness of restorations with bulk-fill resin on one or more surfaces with atraumatic restorative treatment (ART) using conventional GIC. ${ }^{16}$ Another important aspect of this protocol is to test the materials in toddlers up to 36 months, in which the time and ease of application of materials is crucial for treatment success. Due to this, no randomized clinical trials or protocols similar to the purpose of this present study were found, demonstrating its originality.

For being a randomized study, clinical conditions must present the least number of possible external influences and biases. Therefore, this protocol will involve a clinical trial with a split-mouth approach. ${ }^{19}$ Although this may restrict the inclusion of patients in the study, the intention is to place both types of materials under the same conditions, reducing the influence of other factors. In this way, it is believed that a more accurate evaluation of the results can be made.

Gingival bleeding, visible plaque and pufa indices will be applied during clinical examinations. Pufa index assesses the clinical consequences of untreated dental caries: pulpal involvement ( $p)$, ulceration due to trauma from a sharp piece of tooth (u), fistula ( $f$ ), and abscess (a). ${ }^{23}$ These indices will help in the definition of individual caries risk assessment, which is the process establishing the probability of an individual patient, or groups of children, developing carious lesions over a certain time period or the likelihood that there will be a change in size or activity of lesions already present. ${ }^{27,28}$

Only one trained operator will be responsible for performing all restorations. With this strategy, it is expected to minimize the divergence of techniques and to increase the reliability of the procedures.

The dental surgeon will receive pre-clinical training in artificial teeth to learn and improve the technique, which is different for each material. The operator must strictly follow the recommendations of each manufacturer. During the appointments, two assistants will aid the operator, recording time and contributing to the toddlers protective stabilization, if necessary.

In long-term studies that establish different treatments, it is important that blinding be incorporated into the study design to minimize investigator influences on the results and thus obtain valid results, clearer interpretations and highly reliability studies. ${ }^{29}$ Because of that, a double-blind study was chosen, in which the patient and the statistician will be blinded. This blinding will be important because it will ensure parents/guardians provide the same care on both sides of the mouth during their child's oral hygiene. To eliminate any influence of the statistician in the analysis of the results, the restorations will be coded as 1 and 2 and will be revealed only after the analysis of all data. The present clinical trial makes it impossible for the operator and evaluators to be blinded due to clear differences in visual aspects of the materials.

The bulk-fill composite resin was recently introduced on the market and its main differential is the ease technique of application as it can be used in a single increment of up to $4 \mathrm{~mm} \cdot{ }^{15} \mathrm{In}$ addition, is expected that the use of a self-etching together with a single increment approach will allow a faster approach, which is very important in Pediatric Dentistry. It is known that the physical properties of the RMGIC are influenced by the mixing of the material, including its powder/liquid ratio. ${ }^{30}$ Therefore, to minimize the influences of manual preparation, it was decided to use the encapsulated RMGIC. In addition, absolute isolation will be used in both techniques to prevent contact with the oral environment, which would result in possible negative 
influences on the survival of the restorations.

The main outcome of the study will be to evaluate the survival rate of the restorations, considering the integrity of the materials. For this purpose, the Roeleveld criteria ${ }^{26}$ will be used, as in other studies. ${ }^{16,31}$ Since one of the main objectives of a restoration is to protect the dentin-pulp complex and halt the progression of the lesion, ${ }^{9}$ it is more interesting to assess the survival of the restored teeth, considering its importance for the child, than minor failures in the restoration. ${ }^{16}$

Patient-centered outcomes provide means for measuring intervention benefits/risks by evaluating concepts related to how patients feel or function with respect to their health, giving patients a voice in research and health services. ${ }^{32}$ Post-operative sensitivity is an interesting patient-centered outcome to be evaluated in this protocol, since it is expected in patients undergoing restorations, mainly in bulk-fill composite resin, although there is still no scientific evidence on this subject. The B-DDQ ${ }^{25}$ has already been used to measure children's discomfort after dental procedures ${ }^{33}$ and, therefore, it is believed that it will be possible to detect differences, even if slight, between the restorative procedures.

The other secondary outcome that will allow comparison between groups is the cost-effectiveness of the restorations. It is important to analyze the costs of materials and the average time to perform the restorations, especially considering public health policies in developing countries. ${ }^{34}$ In addition, following the principles of evidence-based dentistry, the best treatment at the lowest possible cost should be offered to patients. Therefore, it is expected that this study should be able to establish which material is most costeffective for this type of intervention.

Finally, the operator's preference will be evaluated since the dentist is a fundamental piece to the success of the dental treatment and his/her opinion about the preference for one material should be considered.

\section{CONCLUSION.}

In summary, the protocol will make it possible, under ideal conditions, to determine the most efficacy material for the restoration of cavities in cavities in primary molars of toddlers.
Conflict of interests: The authors declare no conflict of interest.

Ethics approval: This protocol received approval from the Human Research Ethics Committee of the Federal University of Minas Gerais (UFMG), Brazil (CAAE: 12891619.7.0000.5149) and was registered with the Brazilian Registry of Clinical Trials (ReBEC) (www.ensaiosclinicos.gov.br) (UTN number: U11111239-2847).

Funding: This study was supported by the Coordenação de Aperfeiçoamento de Pessoal de Nível Superior (CAPES), Conselho Nacional de Desenvolvimento Científico e Tecnológico (CNPq) and Fundação de Amparo à Pesquisa do Estado de Minas Gerais (FAPEMIG).

Authors' contributions: Ferreira F, Lenzi T FreireMaia F and Martins-Júnior PA conceived the idea. Ferreira F, Lenzi T, Paschoal MA, Paiva S, Freire-Maia $F$ and Martins-Júnior PA participated in protocol design development. Ferreira F, Lenzi T, Paschoal MA, Paiva S, Freire-Maia F, Martins-Júnior PA, Novaes $I C$ and Clementino $L$ participated in the literature review. PAM-J, Clementino L and Novaes IC lead the manuscript drafting. All authors contributed in manuscript drafting and approved the final version of the manuscript.

Acknowledgements: We thank the Coordenação de Aperfeiçoamento de Pessoal de Nível Superior (CAPES), Conselho Nacional de Desenvolvimento Científico e Tecnológico (CNPq) and Fundação de Amparo à Pesquisa do Estado de Minas Gerais (FAPEMIG). 


\section{REFERENCES.}

1. Tinanoff N, Baez RJ, Diaz Guillory C, Donly KJ, Feldens CA, McGrath C, Phantumvanit P, Pitts NB, Seow WK, Sharkov N, Songpaisan Y, Twetman S. Early childhood caries epidemiology, aetiology, risk assessment, societal burden, management, education, and policy: Global perspective. Int J Paediatr Dent. 2019;29(3):238-48.

2. Piva F, Pereira JT, Luz PB, Hugo FN, de Araújo FB. Caries progression as a risk factor for increase in the negative impact on OHRQOL-a longitudinal study. Clin Oral Investig. 2018;22(2):819-28.

3. Boustedt K, Roswall J, Twetman S, Dahlgren J. Influence of mode of delivery, family and nursing determinants on early childhood caries development: a prospective cohort study. Acta Odontol Scand. 2018;76(8):595-9.

4. Evans RW, Feldens CA, Phantunvanit P. A protocol for early childhood caries diagnosis and risk assessment. Community Dent Oral Epidemiol. 2018;46(5):518-25.

5. Twetman S. Prevention of dental caries as a noncommunicable disease. Eur J Oral Sci. 2018;126 Suppl 1:19-25.

6. George A, Sousa MS, Kong AC, Blinkhorn A, Norrie TP, Foster J, Dahlen HG, Ajwan S, Johnson M. Effectiveness of preventive dental programs offered to mothers by non-dental professionals to control early childhood dental caries: a review. BMC Oral Health. 2019;19(1):172.

7. Corrêa-Faria P, Viana KA, Raggio DP, Hosey MT, Costa LR. Recommended procedures for the management of early childhood caries lesions - a scoping review by the Children Experiencing Dental Anxiety: Collaboration on Research and Education (CEDACORE). BMC Oral Health. 2020;20(1):75.

8. Guideline on Caries-risk Assessment and Management for Infants, Children, and Adolescents. Pediatr Dent. 2016;38(6):142-9.

9. Schwendicke F, Göstemeyer G, Blunck U, Paris S, Hsu LY, Tu YK. Directly Placed Restorative Materials: Review and Network Meta-analysis. J Dent Res. 2016;95(6):613-22.

10. Moberg M, Brewster J, Nicholson J, Roberts H. Physical property investigation of contemporary glass ionomer and resin-modified glass ionomer restorative materials. Clin Oral Investig. 2019;23(3):1295-1308.

11. Fronza BM, Ayres A, Pacheco RR, Rueggeberg FA, Dias C, Giannini M. Characterization of Inorganic Filler Content, Mechanical Properties, and Light Transmission of Bulk-fill Resin Composites. Oper Dent. 2017;42(4):445-55.

12. Theobaldo JD, Aguiar FHB, Pini NIP, Lima DANL, Liporoni PCS, Catelan A. Effect of preheating and light-curing unit on physicochemical properties of a bulk fill composite. Clin Cosmet Investig Dent. 2017;9:39-43.

13. Bayraktar Y, Ercan E, Hamidi MM, Çolak H. One-year clinical evaluation of different types of bulk-fill composites. J Investig Clin Dent. 2017;8(2).

14. Pires CW, Pedrotti D, Lenzi TL, Soares FZM, Ziegelmann $\mathrm{PK}$, Rocha RO. Is there a best conventional material for restoring posterior primary teeth? A network meta-analysis. Braz Oral Res. 2018;32:e10.
15. Chesterman J, Jowett A, Gallacher A, Nixon P. Bulk-fill resin-based composite restorative materials: a review. Br Dent J. 2017;222(5):337-44.

16. Olegário IC, Hesse D, Bönecker M, et al. Effectiveness of conventional treatment using bulk-fill composite resin versus Atraumatic Restorative Treatments in primary and permanent dentition: a pragmatic randomized clinical trial. BMC Oral Health. 2016;17(1):34.

17. Oter B, Deniz K, Cehreli SB. Preliminary data on clinical performance of bulk-fill restorations in primary molars. Niger J Clin Pract. 2018;21(11):1484-1491.

18. Akman H, Tosun G. Clinical evaluation of bulk-fill resins and glass ionomer restorative materials: A 1-year followup randomized clinical trial in children. Niger J Clin Pract. 2020;23(4):489-497.

19. Ramfjord SP, Nissle RR, Shick RA, Cooper H Jr. Subgingival curettage versus surgical elimination of periodontal pockets. J Periodontol. 1968;39(3):167-175.

20. Goldman AS, Chen X, Fan M, Frencken JE. Costeffectiveness, in a randomized trial, of glass-ionomerbased and resin sealant materials after 4 yr. Eur J Oral Sci. 2016;124(5):472-9.

21. Roberts JF, Attari N, Sherriff M. The survival of resin modified glass ionomer and stainless steel crown restorations in primary molars, placed in a specialist paediatric dental practice. Br Dent J. 2005;198(7):427-431.

22. Ismail Al, Sohn W, Tellez M, Amaya A, Sen A, Hasson H, Pitts NB. The International Caries Detection and Assessment System (ICDAS): an integrated system for measuring dental caries. Community Dent Oral Epidemiol. 2007;35(3):170-8.

23. Monse B, Heinrich-Weltzien R, Benzian H, Holmgren C, van Palenstein Helderman W. PUFA--an index of clinical consequences of untreated dental caries. Community Dent Oral Epidemiol. 2010;38(1):77-82.

24. Bittencourt JM, Martins LP, Paiva SM, Pordeus IA, Martins-Júnior PA, Bendo CB. Early childhood caries and oral health-related quality of life of Brazilian children: Does parents' resilience act as moderator? Int J Paediatr Dent. 2020.

25. Daher A, Versloot J, Leles CR, Costa LR. Screening preschool children with toothache: validation of the Brazilian version of the Dental Discomfort Questionnaire. Health Qual Life Outcomes. 2014;12:30.

26. Roeleveld AC, van Amerongen WE, Mandari GJ. Influence of residual caries and cervical gaps on the survival rate of Class II glass ionomer restorations. Eur Arch Paediatr Dent. 2006;7(2):85-91.

27. Twetman S. Caries risk assessment in children: how accurate are we? Eur Arch Paediatr Dent. 2016;17:27-32.

28. Tinanoff N, Baez RJ, Diaz Guillory C, Donly KJ, Feldens CA, McGrath C, Phantumvanit P, Pitts NB, Seow WK, Sharkov N, Songpaisan Y, Twetman S. Early childhood caries epidemiology, aetiology, risk assessment, societal burden, management, education, and policy: Global perspective. Int J Paediatr Dent. 2019;29(3):238-48. 
29. Estrada S, Arancibia M, Stojanova J, Papuzinski C. General concepts in biostatistics and clinical epidemiology: Experimental studies with randomized clinical trial design. Medwave. 2020;20(3):e7869.

30. Sidhu SK, Nicholson JW. A Review of Glass-lonomer Cements for Clinical Dentistry. J Funct Biomater. 2016;7(3):16.

31. da Silva GSQ, Raggio DP, Machado GFR, Mello-Moura ACV, Gimenez T, Floriano I, Tedesco TK. Impact of different restorative treatments for deep caries lesion in primary teeth (CEPECO 1) - study protocol for a noninferiority randomized clinical trial. BMC Oral Health. 2019;19(1):6.

32. Perazzo MF, Serra-Negra JM, Firmino RT, Pordeus IA, Martins-Júnior PA, Paiva SM. Patient-centered assessments: how can they be used in dental clinical trials? Braz Oral Res. 2020;34(Suppl 2):e075.
33. Costa LR, Harrison R, Aleksejuniene J, Nouri MR, Gartner A. Factors related to postoperative discomfort in young children following dental rehabilitation under general anesthesia. Pediatr Dent. 2011;33(4):321-6.

34. Gomes HS, Miranda AR, Viana KA, Batista AC, Costa PS, Daher A, Machado GC, Sado-Filho J, Vieira LA, Corrêa-Faria P, Hosey MT, Costa LR. Intranasal sedation using ketamine and midazolam for pediatric dental treatment (NASO): study protocol for a randomized controlled trial. Trials. 2017;18(1):172. 